\title{
TGF $\beta$ signaling supports survival and metastasis of endometrial cancer cells
}

\author{
XiuFen Lei \\ Long Wang \\ Junhua Yang \\ Lu-Zhe Sun
}

Department of Cellular and Structural Biology, the University of Texas Health Science Center, San Antonio, TX 78229, USA
Correspondence: Lu-Zhe Sun

Department of Cellular and Structure Biology, University of Texas Health Science Center, 7703 Floyd Curl Drive, Mail Code 7743, San Antonio, TX 78229-3900, USA

Tel +l 2105675746

Fax + I 2105674664

Email sunl@uthscsa.edu
Abstract: The association of mutation of the transforming growth factor beta (TGF $\beta$ ) type II receptor (RII) with microsatellite instability revealed a significant molecular mechanism of tumorigenesis and tumor progression in gastrointestinal carcinomas with DNA replication error. However, mutation of RII is rare in other types of carcinomas with microsatellite instability including endometrial adenocarcinoma suggesting that TGF $\beta$ receptor signaling may be necessary for tumor progression. To test this hypothesis, we abrogated TGF $\beta$ signaling with ectopic expression of a dominant-negative RII (DNRII) in human endometrial carcinoma HEC-1-A cells with microsatellite instability. Our study showed that over-expression of DNRII blocked the TGF $\beta$ signaling, inhibited anchorage-dependent and -independent growth, and stimulated apoptosis in vitro. Interestingly, the expression of DNRII expression showed little effect on tumor growth of subcutaneously inoculated cells in vivo. On the other hand, the DNRII cells showed more epithelial features whereas the control cells showed more mesenchymal features suggesting a reversal of autocrine TGF $\beta$-induced epithelial-mesenchymal transition (EMT). Consistent with these findings, DNRII cells were much less migratory and invasive in vitro and metastatic in vivo than the control cells. Therefore, an intact TGF $\beta$ signaling pathway appears necessary for the metastatic phenotypes of this carcinoma model.

Keywords: TGF $\beta$, transforming growth factor $\beta$, autocrine TGF $\beta$ signaling, human endometrial cancer, metastasis, epithelial-mesenchymal transition

\section{Introduction}

Transforming growth factor beta (TGF $\beta$ ) superfamily cytokines regulate diverse biological functions including cell proliferation, differentiation, migration, survival and apoptosis. ${ }^{1}$ TGF $\beta$ exerts its effect by binding to a heteromeric complex of transmembrane serine/threonine kinase, the type I (RI) and type II (RII) receptors. Following ligand binding to the RI/RII complex, TGF $\beta$ type I receptor phosphorylates Smad 2 and Smad3, the so called receptor-regulated Smads (R-Smads). Phosphorylated R-Smads form heteromeric complex with Smad4 and translocate into the nucleus to regulate TGF $\beta$-responsive gene transcription. Multiple Smad-independent pathways have also been implicated including MAPK pathways, PI3K pathways, and RhoA. ${ }^{2,3}$

The role of TGF $\beta$ in tumor biology is complex because it can act as both a tumor suppressor and a tumor promoter. ${ }^{4,5}$ TGF $\beta$ elicits the tumor suppressor activity by potently inhibit the proliferation of epithelial, endothelial and haematopoietic cells. However, as tumors evolve, they often evade the TGF $\beta$ growth inhibition due to mutational inactivation or dysregulated expression of various components of the TGF $\beta$ signaling pathways or cell cycle regulatory network. ${ }^{6}$ Several studies demonstrated that abrogation of TGF $\beta$ signaling with the expression of a dominant-negative type II receptor (DNRII) in various tumor cells can impair their motility and tumorigenicity, prevent epithelial-mesenchymal transition (EMT) and reduce their metastatic potential, ${ }^{7-12}$ suggesting that autocrine TGF $\beta$ signaling may promote tumor progression. 
In contrast, DNRII expression increased the skin and prostate cancer metastasis. ${ }^{13,14}$ Clinical studies also showed the contradicting data regarding the patient outcome and loss of RII in tumor cells. ${ }^{15-17}$ All these studies suggest the effect of TGF $\beta$ RII or the effect of autocrine TGF $\beta$ activity is cell/tissue or stage specific.

Endometrial cancer is the fourth leading cancer and the eighth most common cause of cancer death in women in the United States. In 2008, an estimated 40,100 women in the United States are expected to be diagnosed with endometrial cancer, and an estimated 7,470 women are expected to die of the disease. ${ }^{18}$ Most deaths of the cancer are caused by metastases that are resistant to conventional therapies. Therefore, it is important to study the molecular mechanism of endometrial carcinoma metastasis in order to gain insight into better therapies. Endometrial cancer HEC-1-A cell line is TGF $\beta$-sensitive, ${ }^{19,20}$ yet it is defective in the DNA mismatch repair (MMR) genes hPMS2 and hMSH6. ${ }^{21}$ MMR-gene deficient cells are susceptible to progressive accumulation of alterations at microsatellite loci, known as microsatellite instability or RER+ (replication error). Because human TGF $\beta$ RII coding sequence contains a microsatellite sequence, it has been shown to be mutated in colon and gastric cancer cells with deficient DNA MMR and microsatellite instability. ${ }^{22,23}$ However, mutation of human TGF $\beta$ RII was found to be rare in endometrial cancer. ${ }^{23}$ As a RER+ endometrial cancer cell line, HEC-1-A has an operational TGF $\beta$-signaling pathway. Because RII mutation is significantly correlated with longer survival in colon cancer patients, ${ }^{16}$ we hypothesized that TGF $\beta$ receptor signaling may contribute to the malignant properties of HEC-1-A cells. Our study demonstrates that abrogation of TGF $\beta$ receptor signaling with the expression of either a dominant negative RII (DNRII) or a DNRII-EGFP fusion protein in HEC-1-A cells induced apoptosis and reduced invasive and metastatic potential of the cells suggesting that autocrine TGF $\beta$ signaling promotes cell survival and tumor progression.

\section{Materials and methods}

\section{Cell line and cell culture}

Human endometrial carcinoma cell line HEC-1-A was obtained from the American Type Culture Collection and cultured in McCoy $5 \mathrm{~A}$ medium with 10\% fetal bovine serum (FBS), pyruvate, vitamins, amino acids, and antibiotics as previously described. ${ }^{24}$ One pair of HEC-1-A cells was infected with control pLPCX retrovirus vector (Clontech, Mountain View, CA, USA) or pLPCX-DNRII, which expresses a dominant negative RII without the intracellular kinase domain as previously reported. ${ }^{25}$ The stably transfected cells were named as control and DNRII respectively. Another pair of HEC-1-A cells was subsequently infected with the retrovirus vector $\mathrm{pLPCX}$ EGFP, which expresses the enhanced green fluorescence protein, or pLPCX-DNRII-EGFP, which expresses a fusion protein of the DNRII and EGFP. The stably transfected cells were named as control-EGFP and DNRII-EGFP, respectively. It should be noted that the two paired cell lines were produced at different times and were not used in various experiments at the same time. Therefore, even though the data from the two paired cell lines are presented together in the Result section, the data from the control and controlEGFP cannot be compared due to different assay conditions. Working cultures were maintained at $37{ }^{\circ} \mathrm{C}$ in a humidified incubator with $5 \% \mathrm{CO}_{2}$.

\section{Western blot and antibodies}

The cells were rinsed two times with ice-cold PBS and lysed in cell lysis buffer $(50 \mathrm{mM}$ Tris- $\mathrm{HCl} \mathrm{pH} \mathrm{7.4,}$ $150 \mathrm{mM} \mathrm{NaCl}, 1 \%$ Nonidet P-40) containing protease and phosphatase inhibitors (EDTA protease inhibitors, $1 \mathrm{mM}$ $\mathrm{NaVO}_{3}$ and $1 \mathrm{mM} \mathrm{NaF}$; Boehringer Mannheim $\mathrm{GmbH}$, Mannheim, Germany). Equal amounts of protein were separated on SDS-PAGE and transferred to a nitrocellulose membrane (Amersham Corp., Louisville, CO, USA). Blots were blocked in TBST (100 mM Tris- $\mathrm{HCl}$ [pH 8.0], $150 \mathrm{mM} \mathrm{NaCl}, 0.05 \%$ Tween-20) containing 5\% nonfat powder milk. The membrane was then incubated with primary antibody for 1 hour at room temperature or overnight at $4{ }^{\circ} \mathrm{C}$. Antibodies used were phospho-Smad2 (Ser 465/467) (Upstate Biotechnology, Waltham, MA, USA), total Smad2/3 (BD Transduction Laboratories, Lexington, KY, USA), PTEN (Oncogene, Cambridge, MA, USA), phospho-Erk, phospho-p38 and phospho-Akt (Cell Signaling Technology, Danvers, MA, USA). After three washes with TBST, the membrane was incubated with HRP-linked secondary antibody (1:3000; Santa Cruz Biotechnology, Santa Cruz, CA, USA) for $1 \mathrm{~h}$ at room temperature and washed again. Bound complexes were detected using chemiluminescence procedures according to the manufacturer's instructions (NEN Life Science Products, Boston, MA, USA).

\section{Transient transfection and luciferase assay}

To determine the transcription activation by autocrine TGF $\beta$ activity mediated by Smad 3 and Smad4, we measured a TGF $\beta$-responsive promoter activity using 
pSBE4-Luc construct. The promoter activity is reported by luciferase activity. Cells were plated in 12-well plates and co-transfected with the pSBE4-Luc $(0.5 \mu \mathrm{g})$ and a $\beta$-galactosidase expression plasmid $(0.1 \mu \mathrm{g})$ after $24 \mathrm{~h}$ using Fugene6 (Roche Molecular Biochemicals, Indianapolis, IN, USA) according to the manufacturer's instructions. Two hours later, the cells were treated with or without TGF $\beta_{3}(1.0 \mathrm{ng} / \mathrm{ml})$. TGF $\beta_{3}$ was used in the study due to its availability in our lab. It was shown to induce the same cellular responses as TGF $\beta$ in HEC-1-A cells. After another $24 \mathrm{~h}$, cells were lysed and the activities of luciferase and $\beta$-galactosidase were assayed as described previously. ${ }^{25}$ Luciferase activity was normalized to $\beta$-galactosidase activity and expressed as relative luciferase activity.

\section{Anchorage-dependent growth assays}

To study the effect of blockade of autocrine TGF $\beta$ signaling on cell proliferation on plastic, two growth assays were performed. In the first assay, control-EGFP and DNRII-EGFP were plated in 96-well culture plates at 1,000 cells/well and treated with different concentrations of TGF $\beta_{3}$. Relative cell number in each well was determined five days after plating with MTT assay as described previously. ${ }^{26}$ In the second assay, cells were plated in 96-well plates at 1,000 cells/well and treated with or without $1.0 \mathrm{ng} / \mathrm{ml} \mathrm{TGF} \beta_{3}$. Relative cell number was determined with the MTT assay every $48 \mathrm{~h}$ after plating till day 7 .

\section{Soft agarose assay}

To determine the effect of blockade of autocrine TGF $\beta$ signaling on the ability of the cell to grow anchorage-independently in a semisolid medium, soft agarose assays were performed as described previously. ${ }^{26}$ Briefly, $3 \times 10^{3}$ cells were suspended in $1 \mathrm{ml}$ of $0.4 \%$ low melting point agarose (Life Technologies, Carlsbad, CA, USA) dissolved in the regular culture medium and plated on the top of a $1 \mathrm{ml}$ underlayer of $0.8 \%$ agarose in the same medium in six-well culture plates. After four weeks of incubation in the humidified incubator with $5 \% \mathrm{CO}_{2}$ at $37^{\circ} \mathrm{C}$, the cell colonies were visualized by staining with $1 \mathrm{ml}$ of $p$-iodonitrotetrazolium violet staining (Sigma, St Louis, MO, USA).

\section{Cell death detection ELISA}

DNA fragmentation was measured using the Cell Death Detection ELISA kit (Roche Molecular Biochemicals) which is based on detection of cytoplasmic histone-associated-DNAfragments (mono- and oligonucleosomes). The assay was performed as described before. ${ }^{27}$

\section{Tumorigenicity study}

Exponentially growing cultures of HEC-1-A control and DNRII were inoculated subcutaneously in both sides of the rear flank of five-week-old female athymic nude mice (Harlan Sprague Dawley, Inc., Indianapolis, IN, USA) at $2 \times 10^{6}$ cells per site. When the growth of tumors was observed, each xenograft size was monitored twice a week by externally measuring tumors in two dimensions using a caliper. Xenograft volume $(V)$ was determined by the following equation: $V=\left(L \times W^{2}\right) \times 0.5$, where $L$ is the length and $W$ is the width of a xenograft. The use of nude mice for the study was approved by our Institutional Animal Care and Use Committee.

\section{Immuno-cytochemical staining}

Cells were grown on the cover slips in 24-well plate till $80 \%$ confluence. After the cells were fixed in $2 \%$ paraformaldehyde, permeablized in $0.1 \%$ Triton X-100 and blocked with $1.0 \%$ bovine serum albumin, the cells were incubated with an anti-vimentin (Sigma) or anti-E-cadherin (BD Bioscience) antibody for $1 \mathrm{~h}$ at room temperature. After wash, the cells were incubated with fluorescent dye-tagged secondary antibody (Alexa Fluor 594; Molecular Probes, Carlsbad, CA, USA) in the dark for $1 \mathrm{~h}$ at room temperature. After wash, the stained cells were covered with a drop of mounting medium and a cover slip, sealed with nail polish and examined with a confocal fluorescence microscope.

\section{Cell migration and invasion assay}

Cell migration and invasion was determined by using the modified two-chamber migration assay ( $8 \mu \mathrm{m}$ pore size; BD Biosciences) or invasion assay (membrane coated with a layer of Matrigel extracellular matrix proteins) according to the manufacturer's instructions. Cells were seeded in serumfree medium into the upper chamber and migrated/invaded toward the bottom chamber containing a 10\% FBS medium with or without $1.0 \mathrm{ng} / \mathrm{ml} \mathrm{TGF}_{3}$ for $22 \mathrm{hr}$. Cells in the upper chamber were carefully removed using cotton buds and cells at the bottom of the membrane were fixed and stained with HEMA3 Stain Set (Fisher Scientific Company, Pittsburgh, PA, USA). Quantification was performed by counting the stained cells on the entire membrane.

\section{In vivo metastasis assay}

We performed an experimental lung metastasis assay because HEC-1-A cells do not metastasize to lung from subcutaneous tumors in the nude mice and lung is a common metastatic site in patients with advanced and recurrent endometrial 
carcinoma. ${ }^{28}$ Exponentially growing HEC-1-A control-EGFP and DNRII-EGFP cells were injected into tail-vein of five-week-old female athymic nude mice (Harlan Sprague Dawley, Inc.) at 200,000 cells per mouse. Nine weeks later, animals were euthanized, and lungs were removed during autopsy for the detection of metastatic colonies by two methods. First, the EGFP-expressing green metastatic cancer cell colonies were identified and counted using a Nikon fluorescence microscope (TE-200; Nikon Corp., Melville, NY, USA) with a $20 \times$ objective lens $(200 \times$ magnification). Then, the lung tissues were fixed in Bouin's solution (Sigma), and the metastatic nodules on the surface of the lungs were identified and counted with the aid of a magnifier.

\section{Statistical analysis}

Student $t$-tests were used to determine the difference between control and experimental data. ${ }^{29}$

\section{Results}

\section{Expression of DNRII attenuated TGF $\beta$ signaling in HEC-I-A cell}

Human endometrial cancer cell line HEC-1-A is TGF $\beta$ sensitive. In this study, a dominant-negative RII (DNRII) without the cytoplasmic kinase domain was first transfected into HEC-1-A cells for the determination of the role of TGF $\beta$ signaling in their proliferation and apoptosis. Later, a EGFP or a DNRII-EGFP fusion protein was also ectopically expressed in HEC-1-A cells so that metastatic cells can be tracked in vivo. The expression of DNRII or DNRII-EGFP was detected with Western immunoblotting as shown in Figure 1A. It should be noted that because the two paired cell lines were not produced and used at the same time for various experiments, the data from the control and control-EGFP cannot be compared due to variations in assay conditions although the data from the two paired cell lines are presented in the same figure. To determine whether the expression of DNRII or DNRII-EGFP abrogated TGF $\beta$ signaling, we first compared the effect of TGF $\beta$ to induce the phosphorylation of Smad2 (P-Smad2) in the control and DNRII cells. Figure 1B shows that the expression of both DNRII and DNRII-EGFP attenuated TGF $\beta$-induced $\mathrm{P}-\mathrm{Smad} 2$ although the relative reduction of P-Smad2 was more dramatic in DNRII-EGFP cells than in DNRII cells. This is likely in part due to the lower expression level of DNRII than DNRII-EGFP as shown in Figure 1A. Consistently, the blockade of Smad phosphorylation also led to attenuated stimulation of a TGF $\beta$-responsive promoter activity by TGF $\beta$ in the both DNRII and DNRII-EGFP expressing
A

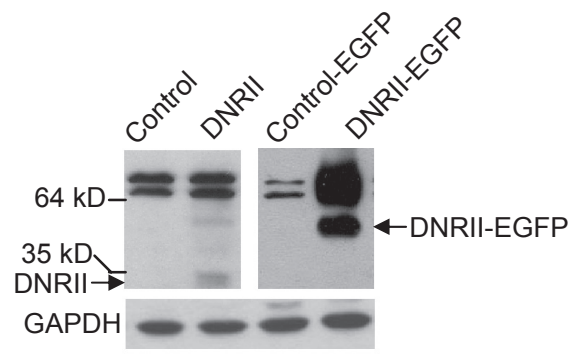

B
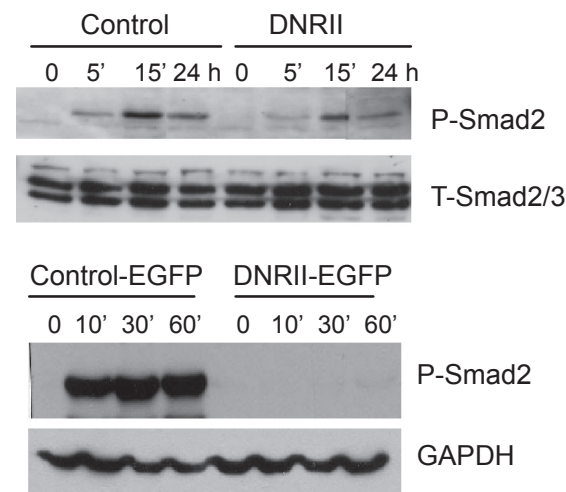

C

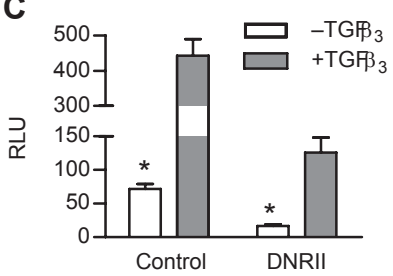

D

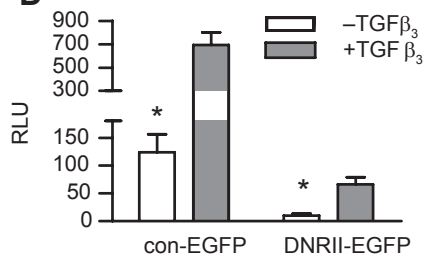

Figure I Effects of DNRII expression on TGF $\beta$ signaling in HEC-I-A cells. A) Expression of DNRII or DNRII-EGFP were detected with Western immunoblotting. GAPDH levels were used to indicate equal sample loading. B) Exponentially growing cultures of the indicated cells were treated with $1.0 \mathrm{ng} / \mathrm{ml}$ of TGF $\beta_{3}$ for different time periods as indicated. Cell lysates were collected for measuring the levels of phosphorylated Smad2 (P-Smad2) and total Smad2/3 with Western immunoblotting as described in the Materials and methods. (C and D) The indicated cells were plated in I2-well plates and transiently transfected with PSBE4-Luc and $\beta$-gal constructs with Fugene6. The transfected cells were treated with or without $1.0 \mathrm{ng} / \mathrm{ml} \mathrm{TGF} \beta_{3}$. The activities of luciferase and $\beta$-gal were measured $24 \mathrm{~h}$ later. Luciferase activity was normalized to $\beta$-gal activity and expressed as relative luciferase unit (RLU). The results plotted represent the means \pm SEM from triplicate transfections.

Notes: *Denotes significant $(\mathrm{P}<0.05)$ difference between control and its respective DNRII cells in the absence of exogenous TGF $\beta_{3}$.

cells (Figures 1C, 1D). It is worth noting that in both pairs of HEC-1-A cells, the basal luciferase activity in control cells was significantly $(\mathrm{p}<0.05)$ higher than that in DNRII cells indicating that the DNRII can antagonize exogenous and endogenous/autocrine TGF $\beta$ activity in HEC-1-A cells.

\section{Autocrine TGF $\beta$ activity supported the growth of HEC-I-A cell}

The growth of HEC-1-A cells was moderately inhibited by TGF $\beta$ in a dose-dependent manner by $23 \%$ at the highest TGF $\beta$ concentration (Figure 2A) and in a time-dependent 
manner by about $40 \%$ on day 7 (Figure $2 \mathrm{~B}$ ). Abrogation of TGF $\beta$ signaling by the expression of DNRII-EGFP abolished the growth inhibitory activity of exogenous TGF $\beta$ as shown in Figures 2A and 2B. Interestingly, DNRII-EGFP cells appeared to grow somewhat slower than control-EGFP cells. The slower growth rate of DNRII-EGFP cells was manifested when cells were plated on soft agarose. The control-EGFP cells formed larger and more colonies than the DNRII-EGFP
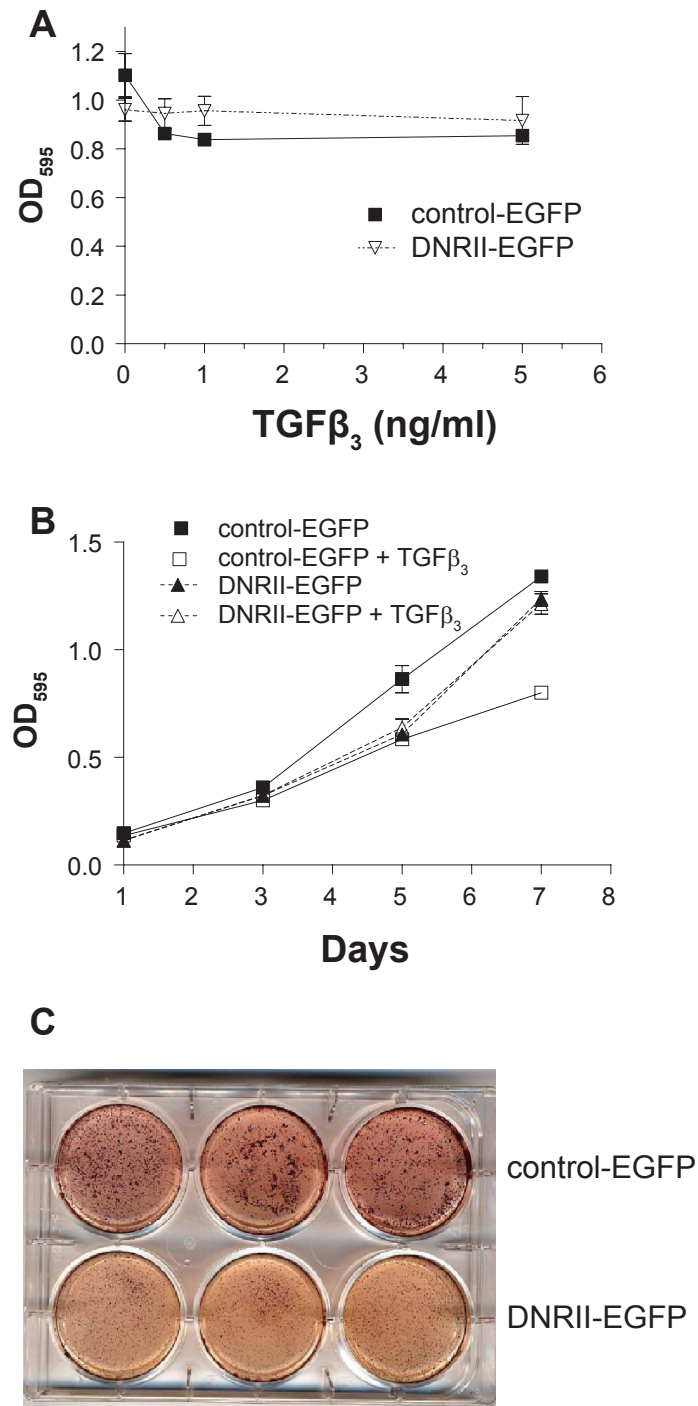

Figure 2 Effect of DNRII expression on the growth of HEC-I-A cells. A) Control-EGFP and DNRII-EGFP cells were plated in a 96 -well plate at 1,000 cell/well and treated with different concentrations of TGF $\beta_{3}$ for five days. Cell number in each well was indirectly measured with MTT assay. Each data point represents the mean \pm SEM from four wells. B) Cells were plated at 1,000 cell/well in 96-well plates and treated with or without TGF $\beta_{3}$ at $1.0 \mathrm{ng} / \mathrm{ml}$. MTT assay was performed every other day till day 7. Each data point represents the mean \pm SEM from four wells. C) Exponentially growing control-EGFP and DNRII-EGFP cells (3,000 cells) were resuspended in $\mathrm{I} \mathrm{ml}$ of $0.4 \%$ low melting point agarose dissolved in the culture medium and placed on top of a I ml under layer of $0.8 \%$ agarose in each well of a six-well plate. After four weeks of incubation, cell colonies were visualized by staining with $1 \mathrm{ml}$ of p-iodonitrotetrozolium violet. cells did when suspended in soft agarose (Figure 2C). These results suggest that autocrine TGF $\beta$ appears to support both anchorage-dependent and anchorage-independent growth of the HEC-1-A cell.

\section{Abrogation of autocrine TGF $\beta$ signaling induced apoptosis in HEC-I-A cell}

The paradoxical observation that both exogenous TGF $\beta$ treatment and abrogation of autocrine TGF $\beta$ signaling inhibited the growth of HEC-1-A cells made us to determine whether autocrine TGF $\beta$ signaling is necessary for the cell survival as we observed in other model systems..$^{25,27}$ Using the Cell Death Detection ELISA Assay, we found that both DNRII and DNRII-EGFP cells were significantly more apoptotic than their respective controls (Figures 3A, 3B). The increased cell death in the DNRII cells was associated with a decreased level of phosphorylated/activated Erk and Akt (Figure 3C), which are known to be activated by TGF $\beta$ signaling. ${ }^{2}$ This is consistent with our previous reports and those by others that autocrine TGF $\beta$-induced activation of Erk and Akt is necessary for supporting cell survival. ${ }^{25,27,30} \mathrm{On}$ the other hand, the levels of phosphorylated p38 and PTEN were not affected in this model system even though they have been shown to be regulated by TGF $\beta$ in other model systems ${ }^{27,31}$ indicating the specificity of the altered levels of phosphorylated Erk and Akt by the blockade of TGF $\beta$
A

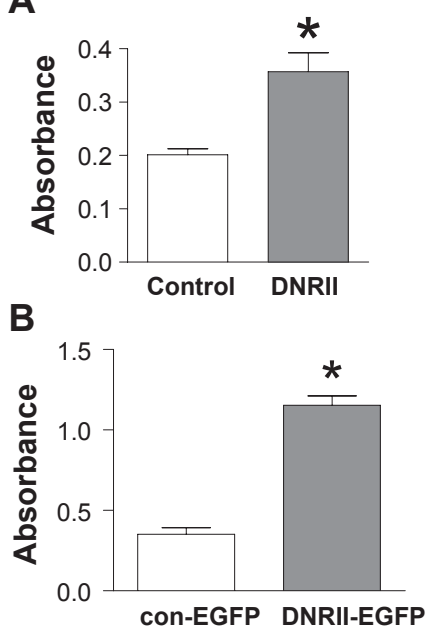

C

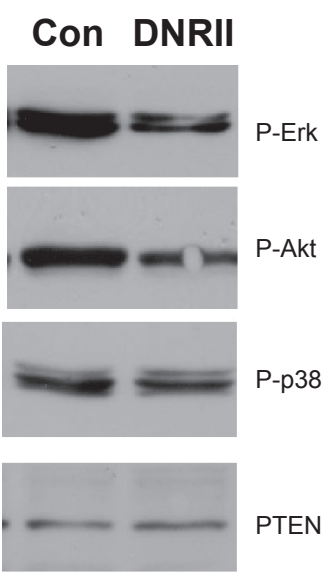

Figure 3 Effect of DNRII expression on apoptosis and activation of Erk and Akt in HEC-I-A cells. A) Control and DNRII cells were cultured in six-well plates and harvested at exponential growth phase. Cell Death Detection ELISA was used to measure apoptosis as described in Materials and methods. The values are presented as means \pm SEM of three optical density measurements from triplicate wells. B) Exponentially growing cultures of the control (con) and DNRIl cells were lysed. Cell lysate were used for measuring the levels of phosphorylated Erk, Akt, and p38, and total PTEN with Western immunoblotting as described in Materials and methods. Note: *Indicates significant difference from the control value at $\mathrm{p}<0.05$. 
signaling. Taken together, these data indicate a biphasic action of TGF $\beta$ signaling in the regulation of the survival and proliferation of HEC-1-A cells.

\section{DNRII expression had no effect on tumorigenicity in vivo}

Because the expression of DNRII was able to suppress the growth and induce apoptosis in vitro, we next tested whether DNRII expression affected the in vivo tumorigenicity of the HEC-1-A cell. Exponentially growing cells of the control and DNRII cells were inoculated subcutaneously in both sides of rear flank of athymic nude mice. Tumor size was monitored and measured externally with a caliper. All inoculated sites developed tumors in both groups. Furthermore, tumors formed by both control and DNRII cells showed a similar growth rate as shown in Figure 4. The experiment was repeated with the control-EGFP and DNRII-EGFP cells and the same results were obtained (data not shown). Thus, blockade of TGF $\beta$ signaling had no effect on tumor incidence and tumor growth rate in this model system.

\section{DNRII expression suppressed EMT, migration, and invasion of HEC-I-A cell} Epithelial-mesenchymal transition (EMT) is believed to contribute to cancer progression. ${ }^{32,33}$ TGF $\beta$ is known to stimulate EMT. ${ }^{34}$ The HEC-1-A control cells showed a low expression of E-cadherin and high expression of vimentin indicating the cells had undergone EMT (Figure 5). Interestingly, these phenotypes were reversed

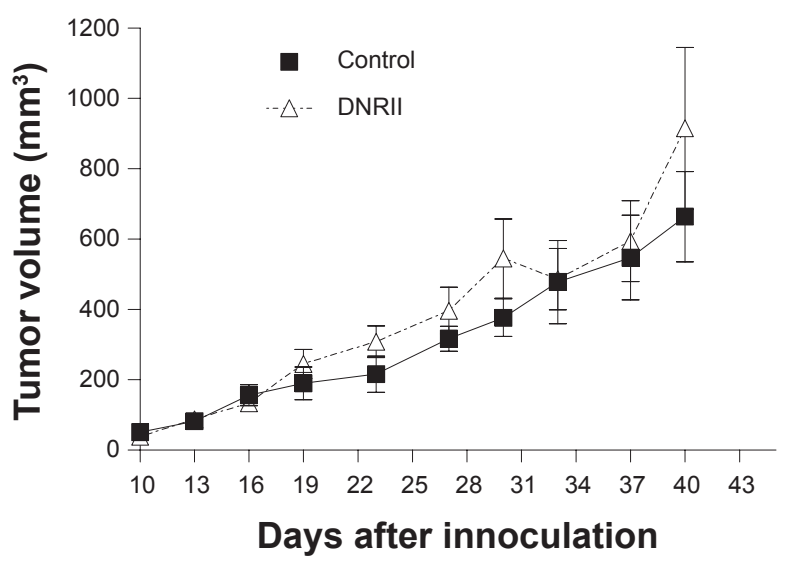

Figure 4 Tumor growth curve of control and DNRII cells in nude mice. Exponentially growing control and DNRII cells were inoculated subcutaneously in both sides of the rear flank of five-week-old female athymic nude mice at $2.0 \times 10^{6}$ per inoculum. The tumor size was measured with a caliper in two dimensions twice a week after the growth of tumors was observed. Tumor volumes were calculated with the equation $V=\left(L \times W^{2}\right) \times 0.5$, where $L$ is length and $W$ is width of a tumor. Values are mean $\pm S E M$ of 12 or 10 tumors formed by control and DNRII cells, respectively.

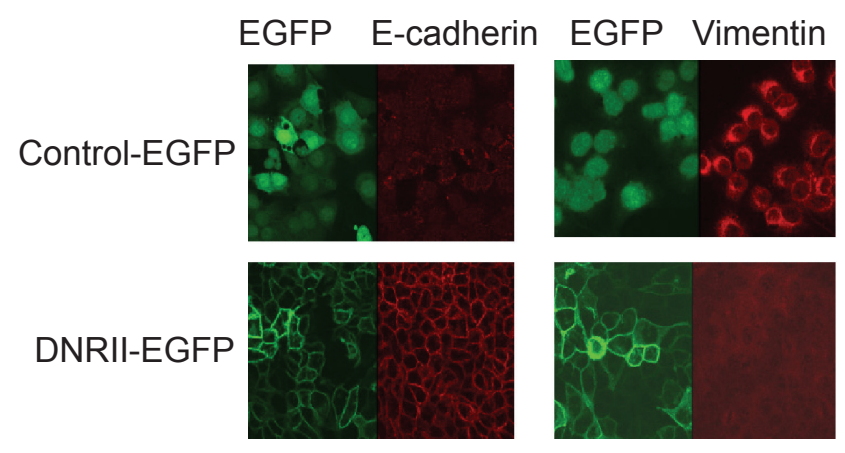

Figure 5 The effect of DNRII expression on the levels of E-cadherin and vimentin. Control-EGFP and DNRII-EGFP cells were grown on cover slips in a 24-well plate till $80 \%$ confluence. The cells were fixed, permeablized, blocked and incubated with an anti-vimentin or anti-E-cadherin antibody for I h at room temperature. After wash, the cells were incubated with a fluorescent dye-tagged secondary antibody. The stained cells were visualized with a confocal fluorescence microscope.

by the expression of DNRII suggesting that the EMT was induced by autocrine TGF $\beta$ signaling (Figure 5). Because EMT is associated with increased cell migration and invasiveness, we next examined whether the expression of DNRII attenuated the migratory and invasive potential of HEC-1-A cells. Using a modified Boyden chamber assay, we found that blockade of autocrine TGF $\beta$ signaling significantly inhibited motility of both DNRII (Figure 6A) and DNRIIEGFP (Figure 6B) cells in comparison with their respective controls. Blockade of TGF $\beta$ signaling also attenuated the invasive potential of the cells through Matrigel as shown in Figures 6C and 6D. The expression of DNRII also abrogated the stimulation of migration and invasion by exogenous TGF $\beta$ (Figures 6A-6C).

\section{Effect of blockade of TGF $\beta$ signaling on the metastasis potential of HEC-I-A cell in vivo}

The inhibition of EMT, migration, and invasion by the abrogation of TGF $\beta$ signaling suggested to us that DNRIIexpressing cells might be less metastatic than the control cells. Because spontaneous distance metastasis was not observed in the mice bearing subcutaneous HEC-1-A tumors, the control-EGFP and DNRII-EGFP cells were injected intravenously through tail vein into athymic nude mice. This experimental lung metastasis assay is particularly relevant because TGF $\beta$ signaling in mammary tumor cells has been shown to promote extravasation in lung ${ }^{35}$ and lung metastasis is observed in endometrial cancer patients. ${ }^{28}$ Metastasis to lung was quantified by counting green fluorescence foci in whole lungs with a fluorescence inverted microscope as well as the number of metastatic nodules on the surface of lungs. 

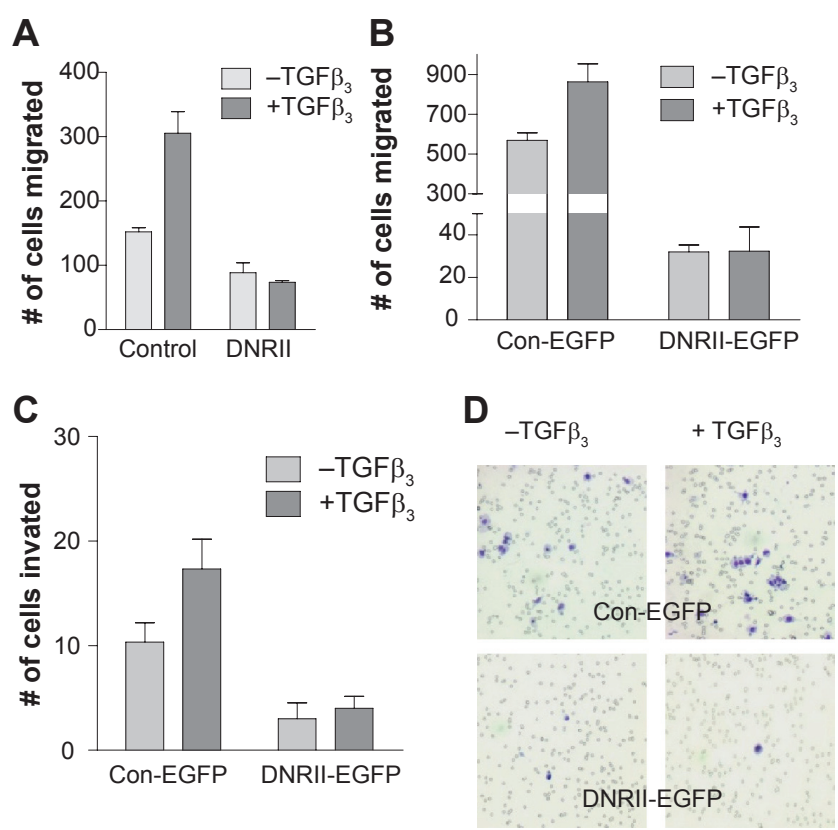

Figure 6 Effect of DNRII expression on cell migration and invasion. HEC-I-A control and DNRII A) or Control-EGFP and DNRII-EGFP B) cells were seeded in serum free medium in the upper chamber. Culture medium containing $10 \%$ FBS with or without $1.0 \mathrm{ng} / \mathrm{ml} \mathrm{TGF} \beta_{3}$ was added in the lower chamber. To test the invasive potential, HEC-I-A control-EGFP and DNRII-EGFP cells $\mathbf{C}$ ) were plated in serum free medium onto the upper chamber coated with a layer of Matrigel. After incubation of $20 \mathrm{~h}$ for panel $\mathrm{A}$ and $24 \mathrm{~h}$ for panel $\mathrm{B}$, the cells on the top of the upper chamber membrane were removed.The migrated or invaded cells on the bottom of the membrane were stained with HEMA3 and visualized under a microscope. A representative example is shown in panel D. Quantification was performed by counting the stained cells on each membrane. Values are means \pm SME from three chambers.

This experimental metastasis assay showed that three out of five animals had lung metastasis in the control-EGFP group, while two out of five animals in DNRII-EGFP group had lung metastasis. More strikingly, for the mice with lung metastasis, the metastasis colonies were much larger (Figure 7A) and more in number in every mouse of the control-GFP group than that in the DNRII-EGFP group (Figures 7B, 7C). These results suggest that TGF $\beta$ signaling promotes the metastatic potential of HEC-1-A cells in vivo.

\section{Discussion}

Mutational inactivation of TGF $\beta$ RII has been frequently observed in hereditary nonpolyposis colorectal carcinoma (HNPCC) cells with a defective DNA mismatch repair system and microsatellite instability. ${ }^{36}$ Paradoxically, RII mutation is significantly rare in endometrial carcinoma with microsatellite instability in HNPCC patients. ${ }^{23}$ Interestingly, RII expression was found to be positively, whereas the expression of Smad2 and Samd4 was found to be negatively, associated with the depth of myometrial invasion in endometrial cancer. ${ }^{37}$ On the other hand, reduced expression of TGF $\beta$ target genes was observed in rat endometrial adenocarcinoma suggesting an attenuation of TGF $\beta$ signaling during the development of the adenocarcinoma. ${ }^{38}$ Because the TGF $\beta$ target genes are mostly regulated via Samd pathway, their reduced expression in the rat endometrial adenocarcinoma could be due to the reduced expression of Smad proteins as observed in human endometrial carcinoma. ${ }^{37}$ On the other hand, TGF $\beta$ binding to its receptors is known to also activate non-Samd pathways such as Ras/MAPK and PI3K/AKT pathways. ${ }^{2}$ Thus, the attenuation of Smad pathway may enhance the tumor-promoting activity of TGF $\beta$ through the activation of Ras/MAPK and PI3K/AKT pathways. Although TGF $\beta$ signaling has been shown to play different, sometimes opposite, role in the regulation of tumor progression in different model systems, how these different effects are played out by the intracellular pathways downstream from its receptors remains to be clarified. In this study, we investigated the role of TGF $\beta$ signaling in the regulation of growth and metastasis of the human endometrial carcinoma HEC-1-A cells by targeting its signaling at the receptor level. Ectopic expression of both DNRII or DNRII-EGFP was shown effective in abrogating TGF $\beta$ signaling. Blockade of autocrine TGF $\beta$ signaling induced apoptosis and inhibited cell migration, invasion and metastatic potential. Although it is not known whether Smad proteins that mediate TGF $\beta$ signaling is down-regulated or not in HEC-1-A cells, our results suggest that in contrast to gastrointestinal tumors, TGF $\beta$ receptor signaling appears to be retained for the survival and progression of certain endometrial cancer cells such as HEC-1-A.

The tumor suppressive activity of TGF $\beta$ pathway is mainly attributed to its inhibition of cell cycle progression from G1 to S phase. Although treatment of HEC-1-A cells with exogenous TGF $\beta$ was shown to moderately inhibit cell proliferation, blockage of TGF $\beta$ signaling did not enhance cell proliferation, but induced cell apoptosis. This was apparently due to the reduced activity of both Erk and Akt pathways as both pathways have been shown previously to mediate autocrine TGF $\beta$-induced cell survival. ${ }^{25,27}$ These observations suggest a biphasic action of TGF $\beta$ signaling in which high levels of TGF $\beta$ signaling can inhibit cell proliferation while very low signaling activity can induce cell death. Thus, while the growth potential is reduced in the DNRII cell due to increased apoptosis, whether the control cell grows at a faster, the same, or slower rate than the DNRII cell appears dependent on the concentration of extracellular TGF $\beta$ as illustrated in Figure 2A. This may explain why the control and DNRII cells formed similar size of tumors when transplanted in vivo even though the DNRII cells were 
A

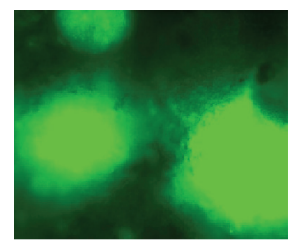

Control-EGFP

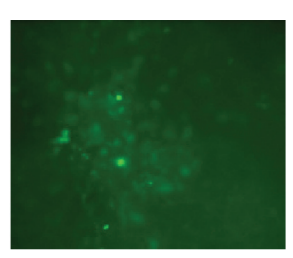

DNRII-EGFP
B

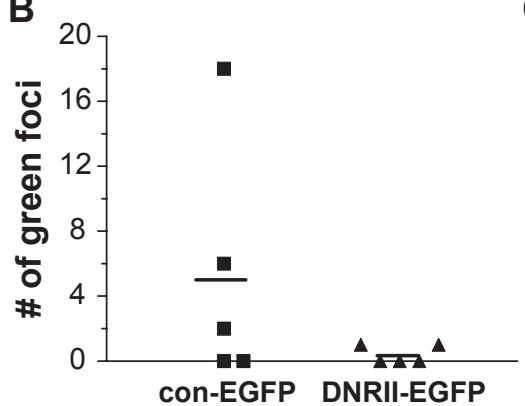

C

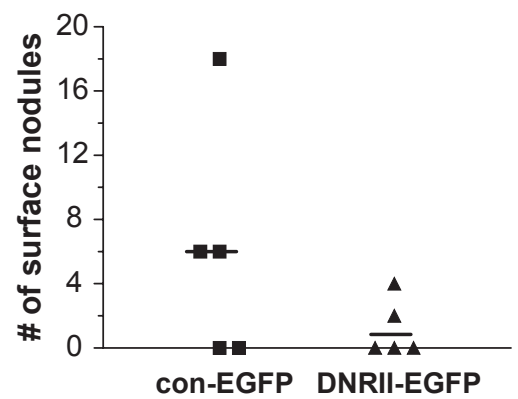

Figure 7 Effect of DNRII expression on in vivo lung metastasis. Exponentially growing control-EGFP and DNRII-EGFP cells $\left(0.2 \times 10^{6}\right)$ were injected into tail veins of five-week-old female athymic nude mice. Five animals were injected for each cell line. After nine weeks, animals were sacrificed, and lungs were removed during autopsy to examine for any metastatic colonies as green fluorescent foci under an inverted fluorescence microscope A). B) The green foci were counted and presented for each of the five animals. C) The excised lungs were subsequently fixed in Bouin's solution. The number of metastatic nodules on the surface of each lung was counted and presented for each of the five animals. The horizontal bars in both panels represent the average number of the metastatic colonies per animal.

more apoptotic in vitro, because tumorigenesis is invariably associated with increased levels of active TGF $\beta$ isoforms in the tumor microenvironment. ${ }^{5}$ The increased TGF $\beta$ signaling may inhibit the growth of control cell-formed tumors, but not the growth of DNRII cell-formed tumors resulting in a similar growth rate between the control and DNRII cellformed tumors. On the other hand, the DNRII cell-formed tumors may be restrained by increased cell death resulting in the similar growth rate as the control tumors. Alternatively, the reason that the increased apoptosis in the DNRII cells in vitro did not translate into slower tumor growth in vivo may be due to gain of cell survival signal from tumor stromal cells in vivo.

Previous studies with TGF $\beta$ inhibitors such as soluble receptors and RI kinase inhibitors showed that systemic administration of these inhibitors had limited to no effect on the growth of orthotopic tumors in mouse mammary glands, but significantly inhibited pulmonary and skeletal metastasis. ${ }^{39-41}$ These observations are consistent with the result that blockade of TGF $\beta$ signaling showed little effect on the tumorigenicity of HEC-1-A cells and suggest that the tumor-promoting activity of TGF $\beta$ mainly resides in the support of metastasis, which results from increased cell migration, invasion, and survival.

Although many signaling pathways have been implicated in the regulation of cell migration and invasion, TGF $\beta$ is known to be a major modulator of tumor cell migration ${ }^{1}$ and invasion, ${ }^{42}$ partly due to its promotion of EMT. ${ }^{43}$ It is believed that during cancer progression, EMT was associated specifically with tumor invasiveness and metastasis. ${ }^{44}$ EMT can be stabilized by autocrine TGF $\beta$ signaling. ${ }^{45}$ Both in vitro experiments with DNRII cell lines ${ }^{9,46}$ and in vivo experiments with DNRII xenograft tumors ${ }^{10}$ demonstrated that DNRII prevents TGF $\beta$-mediated EMT. Conversely, treatment with TGF $\beta$ rendered Ras-transformed epithelial cells fibroblastoid and invasive, and producing more endogenous TGF $\beta$, leading to autocrine maintenance of the invasive phenotype and recruitment of additional cells to become fibroblastoid and invasive. ${ }^{47} \mathrm{~A}$ more recent report showed that DNRII expression abrogated TGF $\beta$ mediated EMT in a transgenic mouse model. ${ }^{48}$ Consistent with these reports, our study showed that DNRII expression reversed the EMT in HEC-1-A cells. In addition, DNRII expression suppressed the cell migration and invasiveness.

The stimulation of cell migration by TGF $\beta$ has been shown to be mediated by both Smad-dependent and Smadindependent pathways including MAP kinase and Akt pathways. ${ }^{3,7,49,50}$ Thus, the reduced levels of activated Erk and Akt in our study are consistent with the reduced cell migration and invasiveness. Approximately, 90\% of colon cancers with microsatellite instability have inactivating mutations of RII. ${ }^{51}$ RII mutation is significantly correlated with favorable chemotherapy treatment outcome and longer patient survival in colon cancer patients suggesting that complete loss of RII in carcinomas may limit systemic metastases. ${ }^{16}$ Our results from the experimental metastasis assay also support this proposition. These observations point to the potential utility of TGF $\beta /$ receptor inhibitors for the treatment of certain advanced endometrial carcinomas as this strategy has been implicated as a potential novel treatment modality in late stage of other carcinomas. ${ }^{52}$

\section{Acknowledgments}

This work was supported in part by NIH grants R01CA075253 and R01CA079683. The authors thank the imaging core facility at their institution for taking the pictures of the 
immunofluorescently stained cells. The authors report no conflicts of interest in this work.

\section{References}

1. Massagué J. TGF $\beta$ signal transduction. Annu Rev Biochem. 1998;67:753-791.

2. Derynck R, Zhang YE. Smad-dependent and Smad-independent pathways in TGF-beta family signalling. Nature. 2003;425(6958):577-584.

3. Bakin AV, Tomlinson AK, Bhowmick NA, Moses HL, Arteaga CL. Phosphatidylinositol 3-kinase function is required for transforming growth factor beta-mediated epithelial to mesenchymal transition and cell migration. J Biol Chem. 2000;275(47):36803-36810.

4. Muraoka-Cook RS, Dumont N, Arteaga CL. Dual role of transforming growth factor beta in mammary tumorigenesis and metastatic progression. Clin Cancer Res. 2005;11(2 Pt 2):937s-943s.

5. Sun L. Tumor-suppressive and promoting function of transforming growth factor beta. Front Biosci. 2004;9:1925-1935.

6. Massague J, Blain SW, Lo RS. TGF-beta signaling in growth control, cancer, and heritable disorders . Cell. 2000;103(2):295-309.

7. Dumont N, Bakin AV, Arteaga CL. Autocrine transforming growth factor-beta signaling mediates Smad-independent motility in human cancer cells. J Biol Chem. 2003;278(5):3275-3285.

8. Yin JJ, Selander K, Chirgwin JM, et al. TGF-beta signaling blockade inhibits PTHrP secretion by breast cancer cells and bone metastases development. J Clin Invest. 1999;103(2):197-206.

9. Oft $\mathrm{M}$, Heider $\mathrm{KH}$, Beug $\mathrm{H}$. TGF $\beta$ signaling is necessary for carcinoma cell invasiveness and metastasis. Curr Biol. 1998;8(23):1243-1252.

10. Portella G, Cumming SA, Liddell J, et al. Transforming growth factor beta is essential for spindle cell conversion of mouse skin carcinoma in vivo: implications for tumor invasion. Cell Growth Differ. 1998;9(5):393-404.

11. McEarchern JA, Kobie JJ, Mack V, et al. Invasion and metastasis of a mammary tumor involves TGF-beta signaling. Int $J$ Cancer. 2001;91(1):76-82.

12. Tang B, Vu M, Booker T, et al. TGF-beta switches from tumor suppressor to prometastatic factor in a model of breast cancer progression. J Clin Invest. 2003;112(7):1116-1124.

13. Go C, Li P, Wang XJ. Blocking transforming growth factor beta signaling in transgenic epidermis accelerates chemical carcinogenesis: a mechanism associated with increased angiogenesis. Cancer Res. 1999;59(12):2861-2868.

14. Tu WH, Thomas TZ, Masumori N, et al. The loss of TGF-beta signaling promotes prostate cancer metastasis. Neoplasia. 2003;5(3): 267-277.

15. Fukai Y, Fukuchi M, Masuda N, et al. Reduced expression of transforming growth factor-beta receptors is an unfavorable prognostic factor in human esophageal squamous cell carcinoma. Int $J$ Cancer. 2003;104(2):161-166.

16. Watanabe T, Wu TT, Catalano PJ, et al. Molecular predictors of survival after adjuvant chemotherapy for colon cancer. $N$ Engl $\mathrm{J}$ Med. 2001;344(16):1196-1206.

17. Miyajima A, Asano T, Seta K, Asano T, Kakoi N, Hayakawa M. Loss of expression of transforming growth factor-beta receptor as a prognostic factor in patients with renal cell carcinoma. Urology. 2003;61(5):1072-1077.

18. Jemal A, Siegel R, Ward E, et al. Cancer statistics, CA Cancer J Clin. 2008;58(2):71-96

19. Presta M, Maier JA, Rusnati M, Moscatelli D, Ragnotti G. Modulation of plasminogen activator activity in human endometrial adenocarcinoma cells by basic fibroblast growth factor and transforming growth factor beta. Cancer Res. 1988;48(22):6384-6389.

20. Bergman CA, Talavera F, Christman GM, Baker VV, Roberts JA, Menon $\mathrm{KM}$. Transforming growth factor-beta negatively modulates proliferation and c-fos expression of the human endometrial adenocarcinoma cell line HEC-1-A. Gynecol Oncol. 1997;65(1):63-68.
21. Glaab WE, Risinger JI, Umar A, Kunkel TA, Barrett JC, Tindall KR. Characterization of distinct human endometrial carcinoma cell lines deficient in mismatch repair that originated from a single tumor. $J$ Biol Chem. 1998;273(41):26662-26669.

22. Markowitz S, Wang J, Myeroff L, et al. Inactivation of the type II TGF-beta receptor in colon cancer cells with microsatellite instability. Science. 1995;268:1336-1338.

23. Myeroff LL, Parsons R, Kim SJ, et al. A transforming growth factor beta receptor type II gene mutation common in colon and gastric but rare in endometrial cancers with microsatellite instability. Cancer Res. 1995;55:5545-5547.

24. Bandyopadhyay A, Cibull ML, Sun LZ. Isolation and characterization of a spontaneously transformed malignant mouse mammary epithelial cell line in culture. Carcinogenesis. 1998;19(11):1907-1911.

25. Lei X, Yang J, Nichols RW, Sun LZ. Abrogation of TGF-beta signaling induces apoptosis through the modulation of MAP kinase pathways in breast cancer cells. Exp Cell Res. 2007;313(8):1687-1695.

26. Sun L, Wu G, Willson JK, et al. Expression of transforming growth factor beta type II receptor leads to reduced malignancy in human breast cancer MCF-7 cells. J Biol Chem. 1994;269:26449-26455.

27. Lei XF, Bandyopadhyay A, Le T, Sun LZ. Autocrine TGF-beta supports growth and survival of human breast cancer MDA-MB-231 cells. Oncogene. 2002;21(49):7514-7523.

28. Bouros D, Papadakis K, Siafakas N, Fuller AF, Jr. Patterns of pulmonary metastasis from uterine cancer. Oncology. 1996;53(5):360-363.

29. Zar JH. Biostatistical Analysis. 2nd ed. Englewood Cliffs, N.J: Prentice-Hall, Inc; 1984

30. Shin I, Bakin AV, Rodeck U, Brunet A, Arteaga CL. Transforming growth factor beta enhances epithelial cell survival via Akt-dependent regulation of FKHRL1. Mol Biol Cell. 2001;12(11):3328-3339.

31. Bakin AV, Rinehart C, Tomlinson AK, Arteaga CL. p38 mitogen-activated protein kinase is required for TGFbeta-mediated fibroblastic transdifferentiation and cell migration. J Cell Sci. 2002;115(Pt 15):3193-3206.

32. Grunert S, Jechlinger M, Beug H. Diverse cellular and molecular mechanisms contribute to epithelial plasticity and metastasis. Nat Rev Mol Cell Biol. 2003;4(8):657-665.

33. Thiery JP. Epithelial-mesenchymal transitions in tumour progression. Nat Rev Cancer. 2002;2(6):442-454.

34. Siegel PM, Massague J. Cytostatic and apoptotic actions of TGF-beta in homeostasis and cancer. Nat Rev Cancer. 2003;3(11):807-821.

35. Siegel PM, Shu W, Cardiff RD, Muller WJ, Massague J. Transforming growth factor beta signaling impairs Neu-induced mammary tumorigenesis while promoting pulmonary metastasis. Proc Natl Acad Sci U S A. 2003;100(14):8430-8435.

36. Markowitz SD, Roberts AB. Tumor suppressor activity of the TGF-beta pathway in human cancers. Cytokine Growth Factor Rev. 1996;7:93-102.

37. Piestrzeniewicz-Ulanska D, Brys M, Semczuk A, Rechberger T, Jakowicki JA, Krajewska WM. TGF-beta signaling is disrupted in endometrioid-type endometrial carcinomas. Gynecol Oncol. 2004;95(1):173-180.

38. Karlsson S, Holmberg E, Askerlund A, Levan KK. Altered transforming growth factor-beta pathway expression pattern in rat endometrial cancer. Cancer Genet Cytogenet. 2007;177(1):43-50.

39. Bandyopadhyay A, Lopez-Casillas F, Malik SN, et al. Antitumor Activity of a Recombinant Soluble Betaglycan in Human Breast Cancer Xenograft. Cancer Res. 2002;62(16):4690-4695.

40. Bandyopadhyay A, Agyin JK, Wang L, et al. Inhibition of Pulmonary and Skeletal Metastasis by a Transforming Growth Factor-\{beta\} Type I Receptor Kinase Inhibitor. Cancer Res. 2006;66(13):6714-6721.

41. Muraoka RS, Dumont N, Ritter CA, et al. Blockade of TGF-beta inhibits mammary tumor cell viability, migration, and metastases. J Clin Invest. 2002;109(12):1551-1559.

42. Seton-Rogers SE, Lu Y, Hines LM, et al. Cooperation of the ErbB2 receptor and transforming growth factor beta in induction of migration and invasion in mammary epithelial cells. Proc Natl Acad Sci U S A. 2004;101(5):1257-1262. 
43. Grunert S, Jechlinger M, Beug H. Diverse cellular and molecular mechanisms contribute to epithelial plasticity and metastasis. Nat Rev Mol Cell Biol. 2003;4(8):657-665.

44. Thiery JP. Epithelial-mesenchymal transitions in tumour progression. Nat Rev Cancer. 2002;2(6):442-454.

45. Janda E, Lehmann K, Killisch I, et al. Ras and TGF beta cooperatively regulate epithelial cell plasticity and metastasis: dissection of Ras signaling pathways. J Cell Biol. 2002;156(2):299-313.

46. Bhowmick NA, Zent R, Ghiassi M, McDonnell M, Moses HL. Integrin beta(1) signaling is necessary for transforming growth factor-beta activation of p38MAPK and epithelial plasticity. $J$ Biol Chem. 2001;276(50):46707-46713.

47. Oft M, Peli J, Rudaz C, Schwarz H, Beug H, Reichmann E. TGF-beta1 and Ha-Ras collaborate in modulating the phenotypic plasticity and invasiveness of epithelial tumor cells. Genes Dev. 1996;10:2462-2477.
48. Han G, Lu SL, Li AG, et al. Distinct mechanisms of TGF-beta1-mediated epithelial-to-mesenchymal transition and metastasis during skin carcinogenesis. J Clin Invest. 2005;115(7):1714-1723.

49. Yu L, Hebert MC, Zhang YE. TGF-beta receptor-activated p38 MAP kinase mediates smad-independent TGF-beta responses. EMBO J. 2002;21(14):3749-3759.

50. Itoh S, Thorikay M, Kowanetz M, et al. Elucidation of Smad requirement in transforming growth factor-beta type I receptor-induced responses. J Biol Chem. 2003;278(6):3751-3761.

51. Parsons R, Myeroff LL, Liu B, et al. Microsatellite instability and mutations of the transforming growth factor beta type II receptor gene in colorectal cancer. Cancer Res. 1995;55:5548-5550.

52. Prud'homme GJ. Pathobiology of transforming growth factor beta in cancer, fibrosis and immunologic disease, and therapeutic considerations. Lab Invest. 2007;87(11):1077-1091. 